\title{
Delineating Subsurface Sewage Flow Path through Directional Fracture Identification in Parts of Owo Area, Southwestern Nigeria
}

\author{
Dorcas S. Eyinla ${ }^{1^{*}}$ and Opeyemi L. Eyinla ${ }^{2}$ \\ ${ }^{1}$ Department of Earth Sciences, Adekunle Ajasin University, Akungba Akoko, Ondo State, Nigeria. \\ ${ }^{2}$ Timikemiki \& Co, Estate Surveyors and Valuers, Suites C10, Poly Plaza Wuse 2, Abuja, Nigeria.
}

Authors' contributions

This work was carried out in collaboration between both authors. Both authors read and approved the final manuscript.

Article Information

DOI: $10.9734 / J G E E S I / 2017 / 15415$

Editor(s):

(1) Mohamed Nageeb Rashed, Department of Chemistry, Aswan University, Egypt.

Reviewers:

(1) Spinosa Ludovico, Italy.

(2) Joseph D. Rouse, University of Guam, USA.

(3) A. Akinlalu Ayokunle, Federal University of Technology, Akure, Ondo State, Nigeria. Complete Peer review History: http://www.sciencedomain.org/review-history/19104

Original Research Article

Received $25^{\text {th }}$ November 2014

Accepted $16^{\text {th }}$ January 2015

Published $17^{\text {th }}$ May 2017

\begin{abstract}
The disposal of waste materials by burial is the oldest form of solid waste disposal. A major concern with the usage of traditional dump sites is the potential of polluting groundwater. The pollution could be metals, microbes or other substances. This problem of groundwater contamination from refuse disposal especially those located uphill are worsened when communities that rely on dump site disposal system also depend on private wells for drinking water. Wastewater often makes its way into other water bodies. Water runoff from rain may wash contaminants into the surface waters. A more significant hazard is when pollutants from the drain field move quickly through the soil and potentially into the groundwater making the supposed potable water unusable. The application of methods involving identification of anisotropic behavior and heterogeneities in rocks has become increasingly acceptable because these methods provide adequate knowledge about the presence of fractures and their directions. Observed changes in apparent resistivity with azimuth are typically used for such interpretation which indicates fracture anisotropy. Due to repeated cases of groundwater pollution in the area, this study researches into the application of surface geophysical
\end{abstract}


methods to detect bedrock fractures and to estimate hydraulic properties of the fractured bedrock in order to determine the direction of wastewater flow from a dump site located uphill into a public borehole. Azimuthal Square array was used to detect fractures in bedrock in parts of Owo area in Ondo State, Nigeria. Apparent resistivities measured at four locations near the dumpsite changed with the orientation of the array. Scattered plots and Graphical interpretation of the technique indicate that a dominant fracture set is oriented NW/SE. Hydrochemical analysis of water samples collected from three hand dug wells around the dump revealed presence of leachates. The presence and interconnectivity of fracture zones in almost all the sampled points even at the over burden in the study area provide pathway for easy movement of the waste water.

Keywords: Dump site; leachate; water pollution; Azimuthal square array; fracture; anisotropy.

\section{INTRODUCTION}

One part of this study assesses the ability of direct-current $(\mathrm{dc})$ resistivity methods to detect bedrock fractures. Till now, Dc-resistivity methods have been successfully used by a number of investigators to detect bedrock fractures [1-20]. Most of these investigations have used collinear arrays (Wenner or Schlumberger) rotated about a fixed center point to measure azimuthal variations in apparent resistivity that are related to sets of similarly oriented, steeply dipping fractures [21].

Habberjam [22] showed that a square array is more sensitive to anisotropy in the subsurface and requires less surface area than collinear arrays. Recently, dc-resistivity surveys using a square array have been conducted to detect productive fracture zones in crystalline bedrock for ground-water supply [23-24]. These studies verified Habberjam's earlier work, showing that the square array has a greater sensitivity to a given bedrock anisotropy and requires less surface area than collinear arrays. This prompted the use of a square array for this study in parts of the Owo area in order to detect subsurface fractures liable to contributing to ground water pollution in the area due to the placement of a dump site uphill of the borehole. Azimuthal Resistivity Soundings were also carried out at the same locations to further verify the presence of subsurface features. To verify the presence of leachates from the dump site, water samples were taken from three hand dug wells at an average depth of $3.5 \mathrm{~m}$ around the dump site for hydrochemical analysis.

\subsection{Location and Geology of the Study Area}

The area under study is located in Owo in Ondo State, Southwestern Nigeria. It is situated between latitudes $7^{\circ} 10^{\prime} \mathrm{N}$ and $7^{\circ} 11^{\prime} \mathrm{N}$, and longitudes $5^{\circ} 34^{\prime} \mathrm{E}$ and $5^{\circ} 36^{\prime} \mathrm{E}$ (Fig. 1). Geologically, the area is situated on the Basement Complex of Nigeria which marks about $50 \%$ of the total area of Nigeria. The rocks underlying the area are the Migmatite-Gneiss Complex (MGC) rocks. The geological survey earlier carried out in the area showed that the site where this investigation was carried out comprises of Migmatite and Undifferentiated Schist. The geological map of the study area is shown in Fig. 2.

\subsection{Theoretical Background}

The square array was originally developed as an alternative to Wenner or Schlumberger arrays when a dipping subsurface, bedding, or foliation was present [25]. Habberjam [26] gave a complete discussion of the square array and methods of data analysis.

Geoelectrical resistivity field data are acquired using earth resistivity meter commonly referred to as Terrameter. The equipment is portable, light weight and relatively cost effective when compared with other geophysical data acquisition systems. A dc-resistivity survey using the square-array method is conducted in a manner similar to that for traditional collinear arrays. The location of a measurement is assigned to the center point of the square. The array size $(A)$ is the length of the side of the square. The array is expanded symmetrically about the center point, in increments of $A(2)^{1 / 2}$ so that the sounding can be interpreted as a function of depth [25].

For each square, three resistivity measurements are made, two perpendicular measurements (alpha, $\alpha$ and Beta, $\beta$ ) and one diagonal measurement (Gamma, y) (Fig. 3). The $\alpha$ and $\beta$ measurements provide information on the directional variation of the subsurface apparent resistivity ( $\rho a, \Omega m)$. 
The azimuthal orientation of the $(\alpha)$ and $(\beta)$ measurements is that of the line connecting the current electrodes. The measurement serves as a check on the accuracy of the measurements.

$A B$ represents current electrodes while $M N$ represents potential electrodes.

In an isotropic medium,

$$
\rho_{a_{\alpha}}=\rho_{a_{\beta}} \text { therefore } \rho_{a_{\lambda}}=0
$$

And in a homogeneous anisotropic medium,

$$
\rho_{a_{\lambda}}=\rho_{a_{\alpha}}-\rho_{a_{\alpha}}
$$

Where $\rho_{\mathrm{a}}=$ apparent resistivity $(\Omega \mathrm{m})$. Apparent resistivity is determined using the equation:

$$
\rho_{a}=\frac{K \Delta V}{I}
$$

$\mathrm{K}=$ geometric factor for the array; $\Delta \mathrm{V}=$ potential difference, in V; and I= current magnitude, in $\mathrm{A}$.

For the square array,

$$
\mathrm{K}=\frac{2 \pi A}{2-(2)^{1 / 2}}
$$

Where $A=$ square-array side length, in meters [25].

\subsection{Sensitivity to Anisotropy}

To correctly interpret azimuthal dc-resistivity data over fractured rock, the bedrock must behave as an anisotropic medium. Satisfying this requires the electrode spacing to be large with respect to the fracture spacing [5]. The square array has been shown to be more sensitive to anisotropy than the Schlumberger or Wenner array [22-23]. For the square array, the ratio of apparent resistivity measured perpendicular to fracture strike $\left(\rho_{\text {at }}\right)$ to apparent resistivity parallel to fracture strike $\left(\rho_{\mathrm{a} 1}\right)$ is called the apparent anisotropy $\left(\lambda_{a}\right)$.

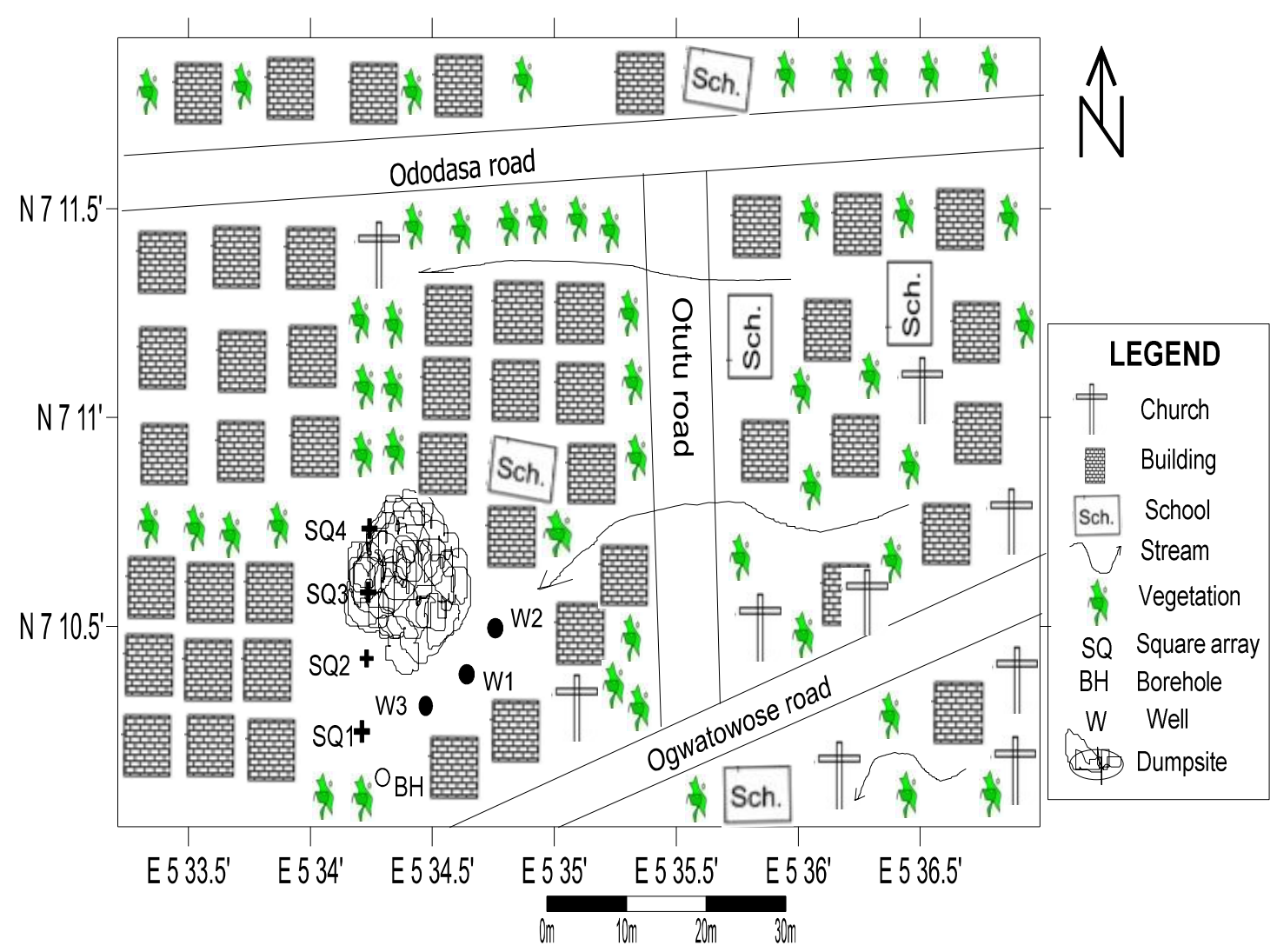

Fig. 1. Base map of the study area 


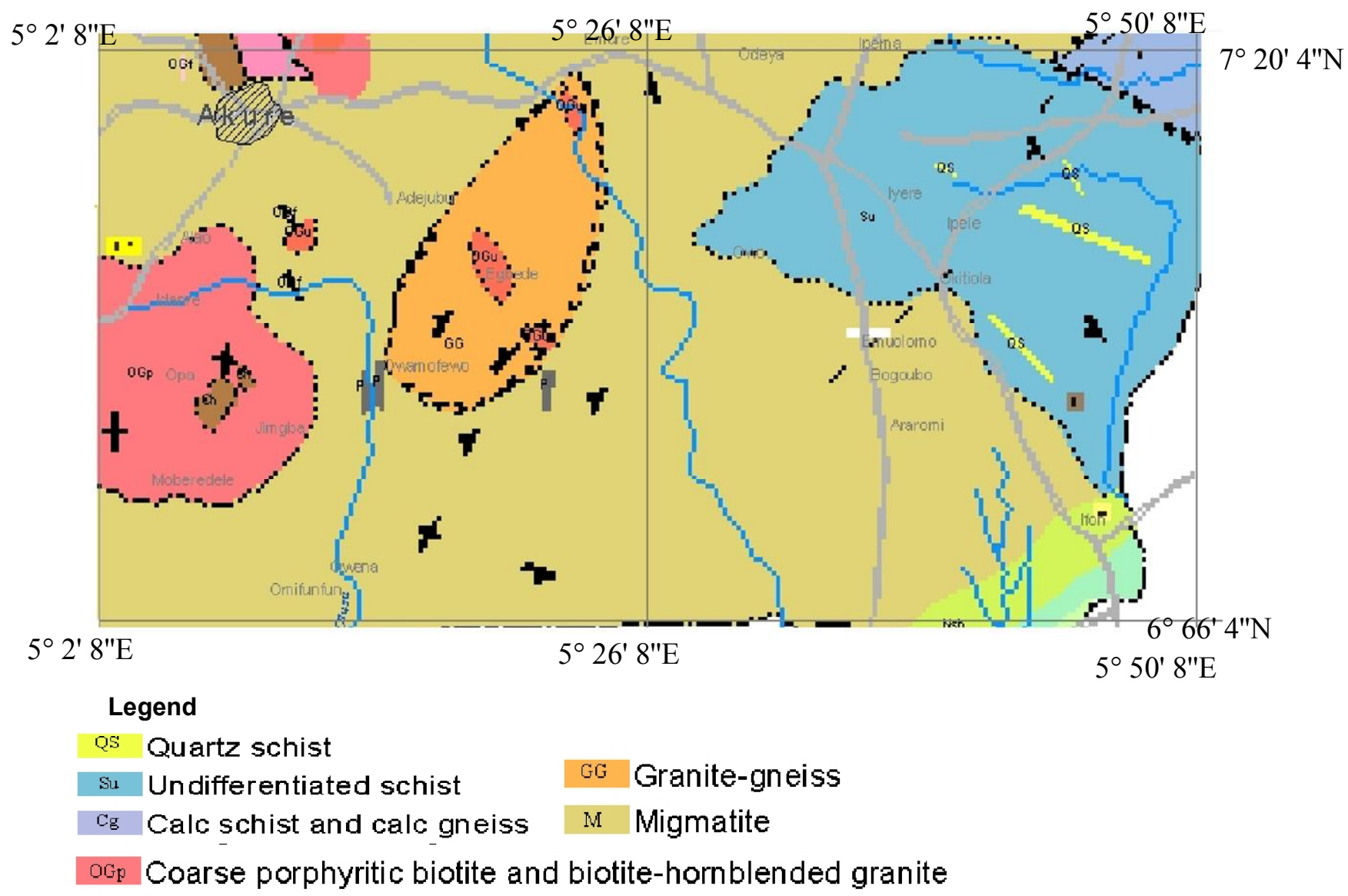

SA - Study Area

Fig. 2. Geological map of the study area (Extracted from geological map of Ondo State by NGSA) 

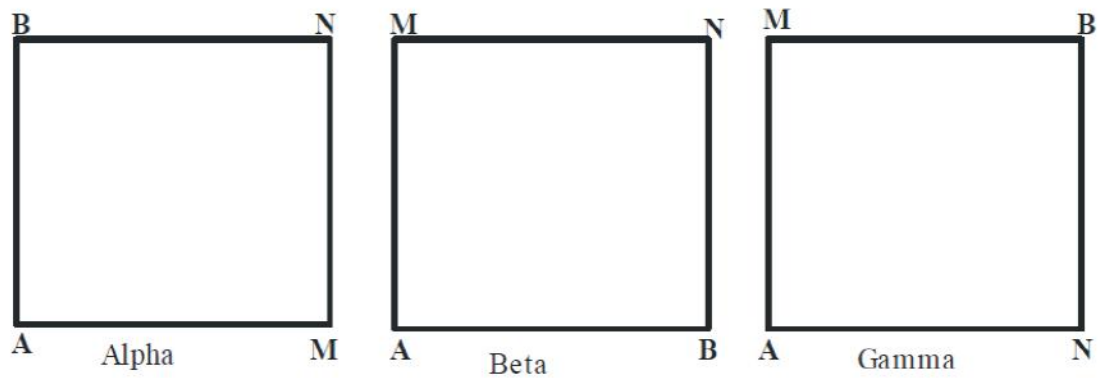

Fig. 3. Electrode position for square-array measurement

\section{METHODOLOGY}

The main field equipment employed for this work was the ABEM Terrameter SAS 300 . It is a single unit consisting of a transmitter, a receiver, and a microprocessor. Other accessories of the SAS 300 used include the current cables, potential cables, stainless steel electrodes of length about $57 \mathrm{~cm}$, Nickel-Cadmium batteries, battery charger and Global positioning system (GPS).

A total of four locations were sampled with 5-m intervals and the locations are denoted as ASA 01 to ASA 04. At each of these locations, electrical resistivity survey was carried out using the square array technique along four directions; N/S, E/W, NE/SW, NW/SE corresponding to $90^{\circ}$, $180^{\circ}, 270^{\circ}$ and $360^{\circ}$.

The maximum spread of $A B / 2$ is $70 \mathrm{~m}$. Lines of the resistivity of the same value along different azimuths were joined together, thus resulting in a polygon. A set of such polygons obtained corresponding to different $A B / 2$ separations is known as a polar diagram or anisotropy polygon. For an isotropic homogeneous formation, this polygon will assume a circular shape. Any deviation from a circle to an ellipse is indicative of anisotropic nature of the formation [6]. The major or longest axis of the ellipse, which can fit any of such anisotropic polygons, gives the strike direction of the fracture.

Coefficient of anisotropy is a useful parameter of an anisotropic medium and can be estimated as:

$$
\lambda \mathrm{a}=\sqrt{\rho_{a t} / \rho_{a s}}
$$

The co-efficient of apparent anisotropy $(\lambda a)$ which is designated here as the degree of fracturing is calculated from each anisotropy ellipse fitted through each polygon.

The calculated values of $\lambda \mathrm{a}$ are then plotted against the corresponding $A B / 2$ separations. The behavior of rock fracturing at various depth equivalents to different $A B / 2$ separations can thus be understood qualitatively from the variation of $\lambda$ a. For this study, the apparent resistivity anisotropy polygon was plotted and coefficient of anisotropy was calculated for each station, using the methods of Habberjam and others [22-29].

\section{RESULTS AND DISCUSSION}

Data collected were analyzed by plotting the apparent resistivity against the azimuth for each electrode spacing of the Azimuthal Square Array. Fracture strike can be determined graphically or analytically. In this work, the graphical analysis mode was used. Here, the values of apparent resistivity measurements for each square orientation are plotted against the azimuth for that square yielding anisotropic polygons (Fig. 4). The anisotropy polygons were gotten by selecting specific distances of $A B / 2$ using $1.4 \mathrm{~m}$, $14.1 \mathrm{~m} 21.1 \mathrm{~m}, 28.3 \mathrm{~m}, 35.4 \mathrm{~m}, 42.4 \mathrm{~m}$ and $49.5 \mathrm{~m}$. From the resulting azimuthal plot according to Habberjam [22], the principal fracture strike direction for azimuthal squarearray plot is perpendicular to the direction of maximum measured apparent resistivity. The radial plot is used to describe fracture directions at specific positions. The concise interpretation of this study has clearly brought out the subsurface fracture orientation.

The interpreted fracture directions for the selected anisotropic polygon plots are summarized in Table 1 , indicating the major or longest axis of the ellipse, which can fit any of such anisotropic polygons. This gives the strike direction of the fracture. 
Eyinla and Eyinla; JGEESI, 10(2): 1-11, 2017; Article no.JGEESI.15415

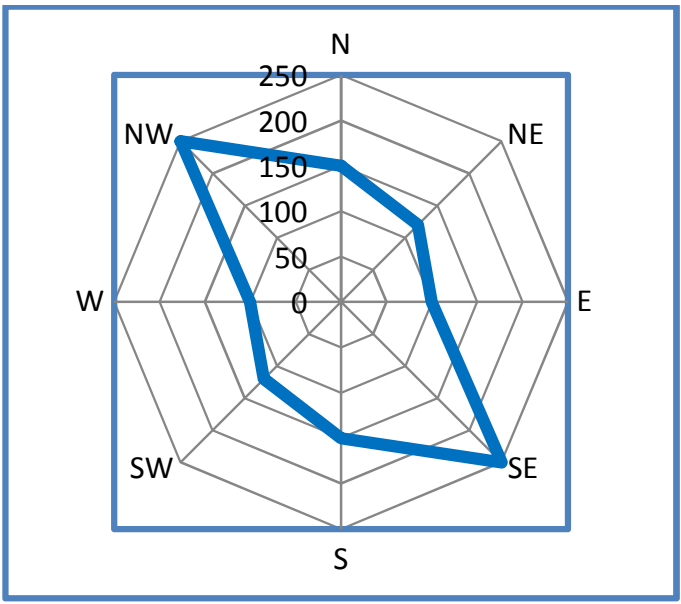

(a)

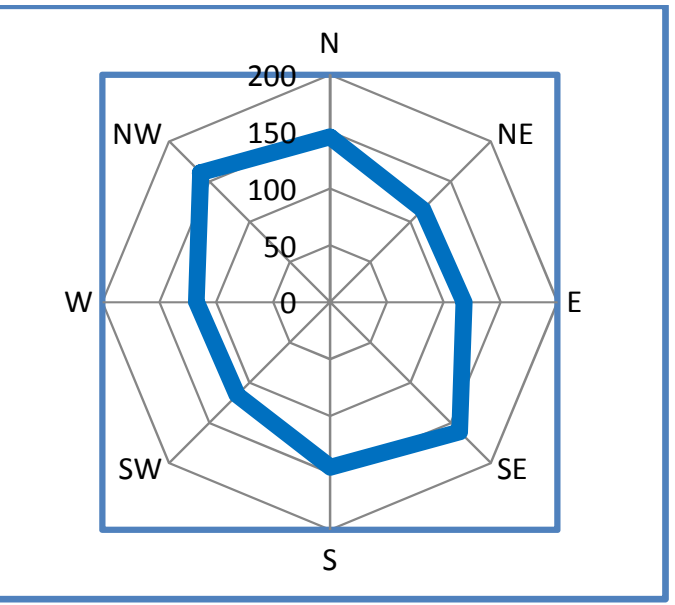

(c)

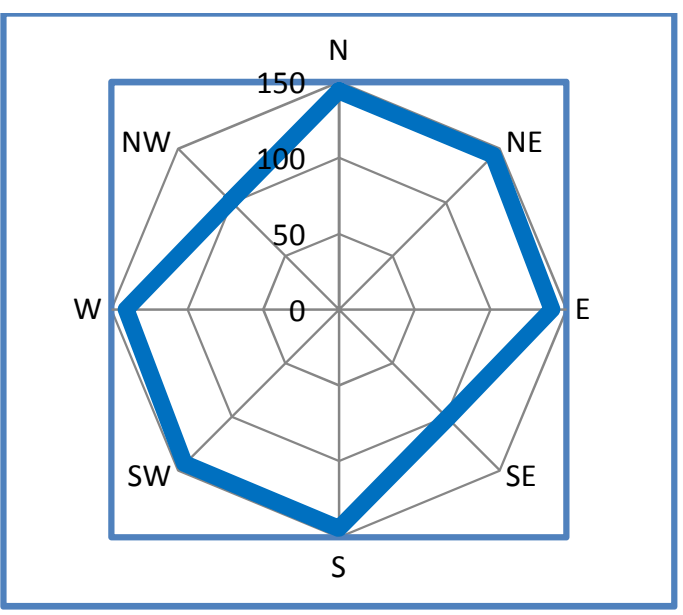

(e)

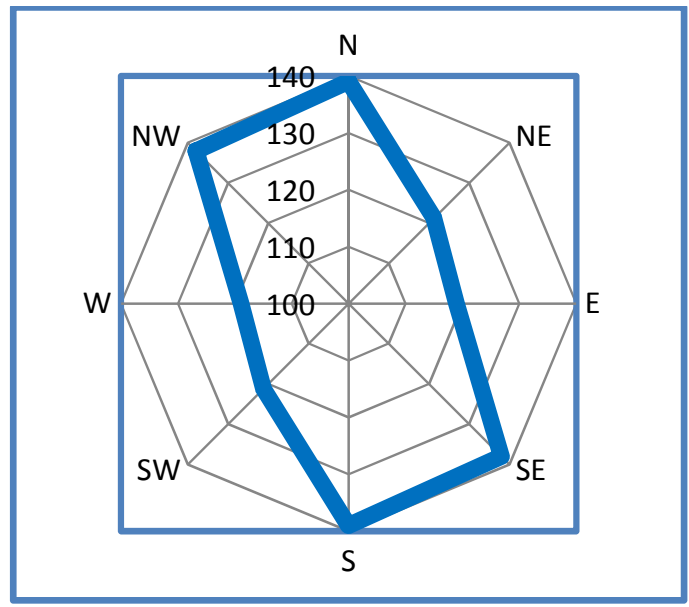

(b)

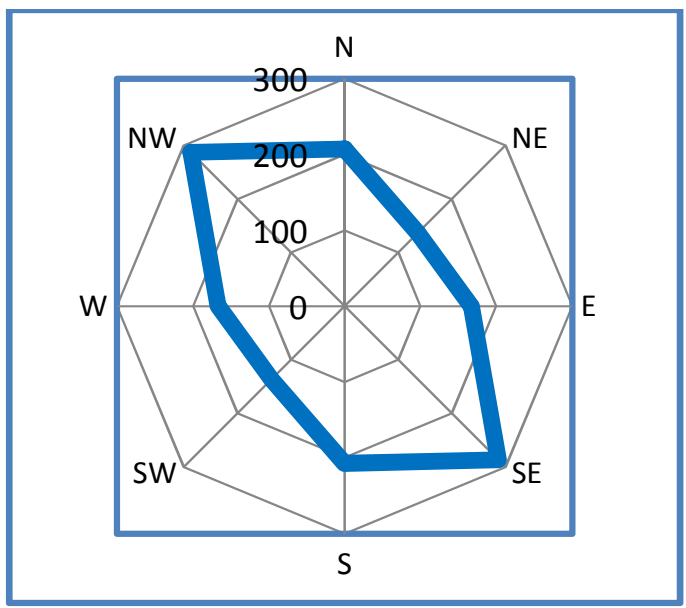

(d)

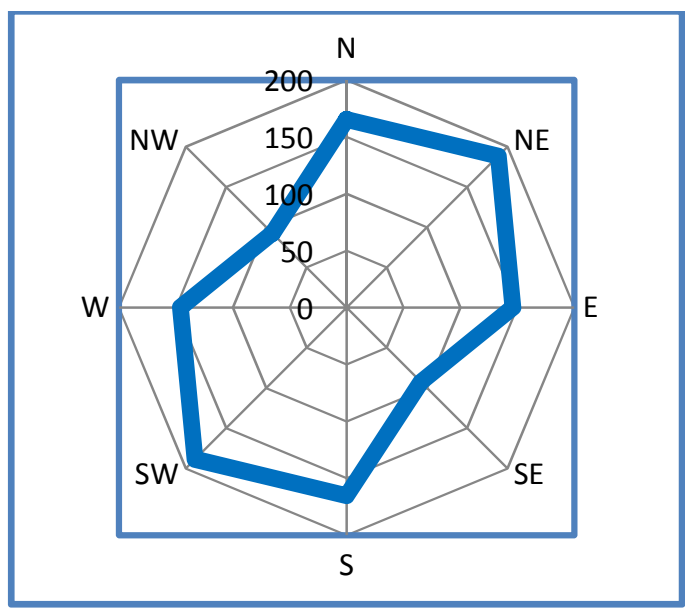

(f) 


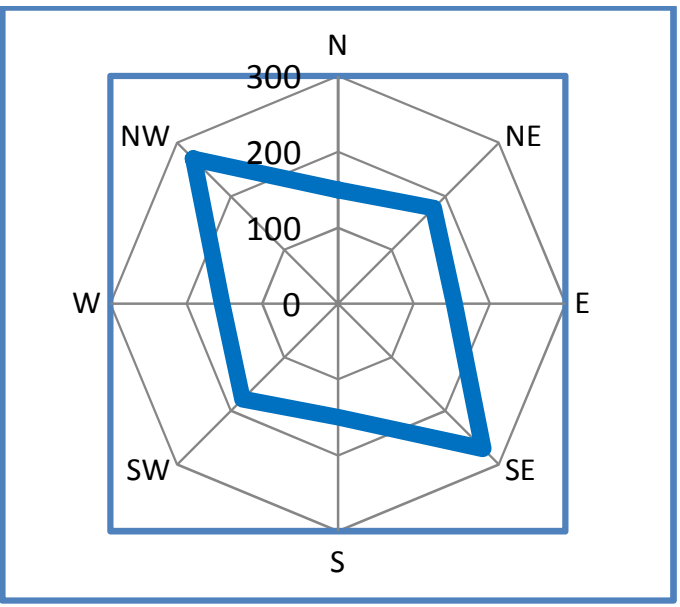

(g)

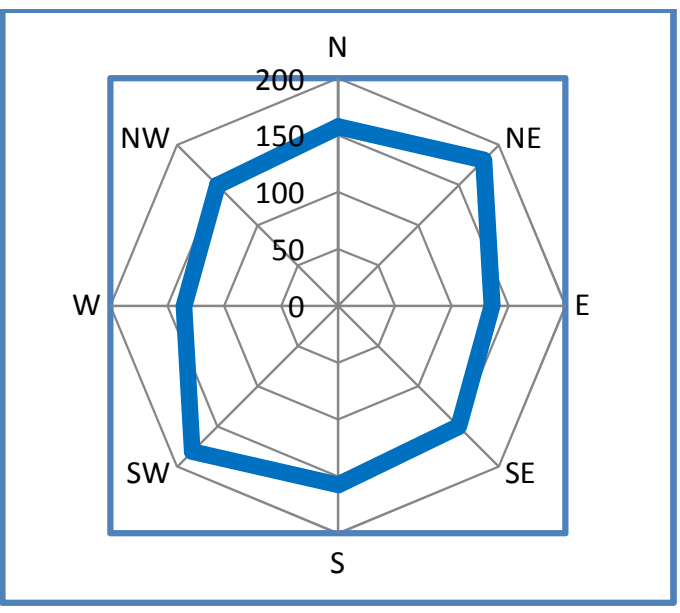

(i)

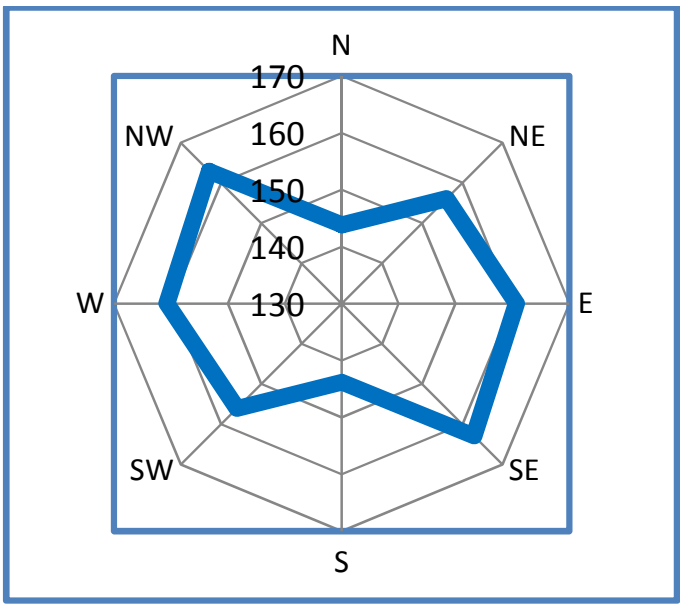

(h)

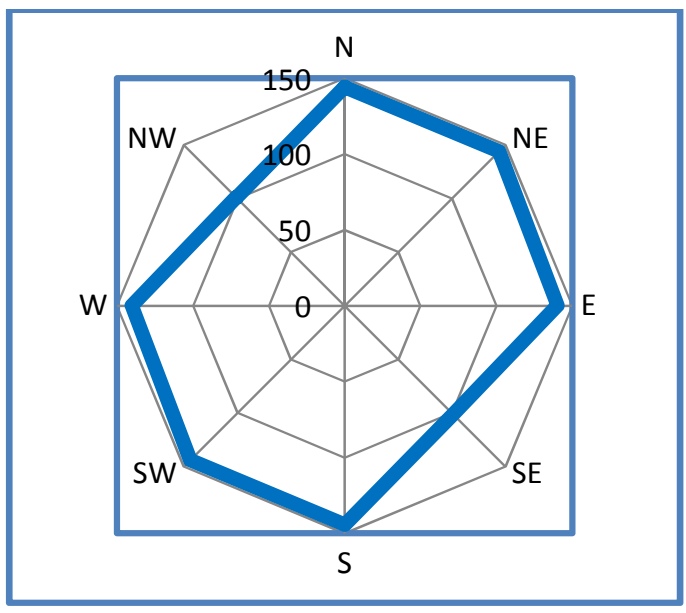

(j)

Fig. 4. Square plots at different $A B / 2$ and Location

(a) $1.4 \mathrm{~m}$, ASA 01, (b) $14.1 \mathrm{~m}$, ASA01, (c) $28.3 \mathrm{~m}$, ASA 01, (d) 35.4 m, ASA 01, (e) $42.4 \mathrm{~m}$, ASA 01, (f) 49.5 m, ASA 01, (g) $14.1 \mathrm{~m}, \mathrm{ASA} 02$, (h) $21.1 \mathrm{~m}$, ASA 02, (i) $42.4 \mathrm{~m}$, ASA 03, (j) $49.5 \mathrm{~m}$, ASA04

Table 1. Fracture direction of some prominent points at each location

\begin{tabular}{lll}
\hline Location & Selected points AB/2 (Square array) & Fracture direction \\
\hline ASA 01 & $1.4 \mathrm{~m}, 14.1 \mathrm{~m}$ and $35 \mathrm{~m}$ & $\mathrm{NW} / \mathrm{SE}$ \\
& $49.5 \mathrm{~m}$ & $\mathrm{NE} / \mathrm{SW}$ \\
ASA 02 & $14.1 \mathrm{~m}$ & $\mathrm{NW} / \mathrm{SE}$ \\
& $21.1 \mathrm{~m}$ & $\mathrm{~W} / \mathrm{E}$ \\
& $42.4 \mathrm{~m}$ & $\mathrm{NE} / \mathrm{SW}$ \\
ASA 03 & $1.4 \mathrm{~m}$ & $\mathrm{NW} / \mathrm{SE}$ \\
& $14.1 \mathrm{~m}$ & $\mathrm{~N} / \mathrm{S}$ \\
ASA 04 & $14.1 \mathrm{~m}$ & $\mathrm{NW} / \mathrm{SE}$ \\
& 28.3 & $\mathrm{NW} / \mathrm{SE}$ \\
\hline
\end{tabular}

The values of coefficient of anisotropy (COA) calculated for each location are presented in Table 2, and were used to plot scatter diagrams. These scatter diagrams were interpreted to describe the degree of fracture with respect to depth at different 
electrode spacing (Figs. 5-8). Arrows on certain points on each plot indicate areas with intense fracture. Higher values of COA indicate

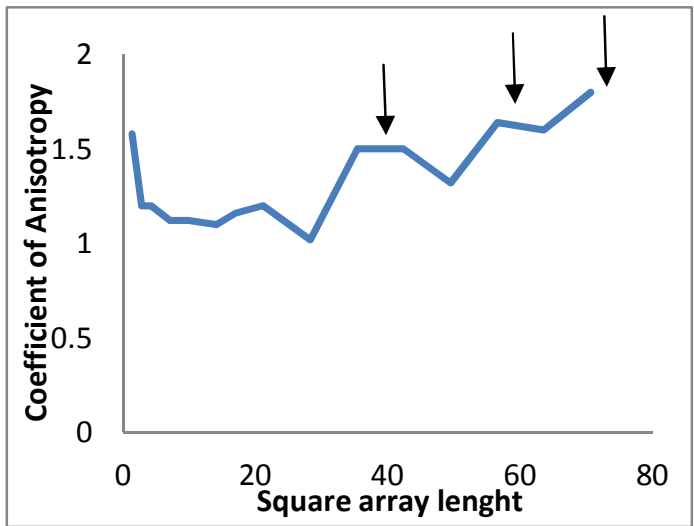

Fig. 5. Scatter plot for location 1

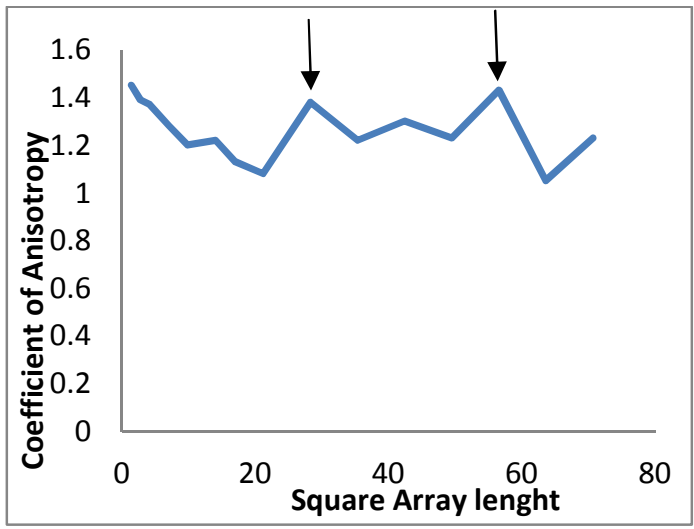

Fig. 7. Scatter plot for location 3 high degree of fracturing. Table 3 gives the summary of the intensity of fracturing at each location.

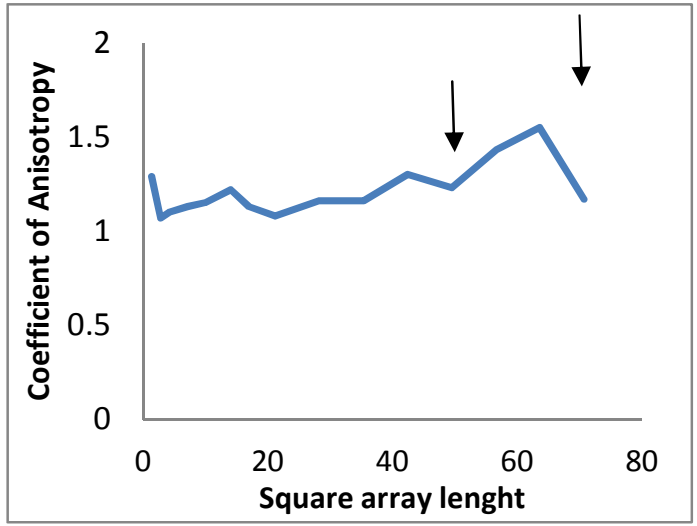

Fig. 6. Scatter plot for location 2

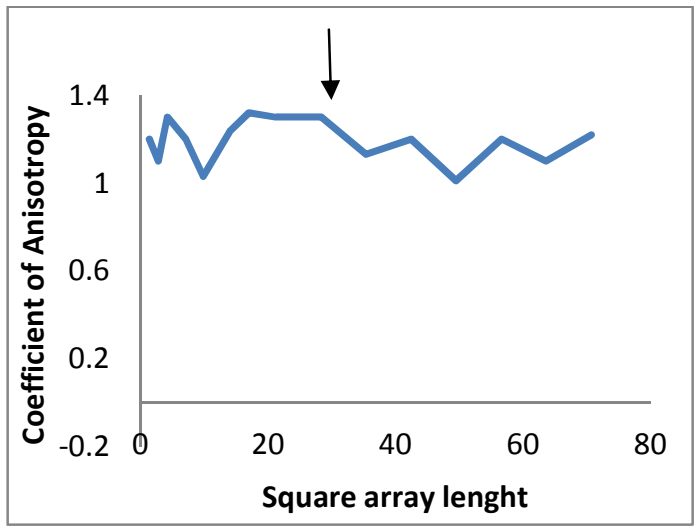

Fig. 8. Scatter plot for location 4

Table 2. The coefficient of anisotropy for square array at each location

\begin{tabular}{lllll}
\hline $\mathbf{A B} / \mathbf{2}$ & Location 1 & Location 2 & Location 3 & Location 4 \\
\hline 1.4 & 1.58 & 1.29 & 1.45 & 1.2 \\
2.8 & 1.2 & 1.07 & 1.39 & 1.1 \\
4.2 & 1.2 & 1.1 & 1.37 & 1.3 \\
7.1 & 1.12 & 1.13 & 1.28 & 1.2 \\
9.9 & 1.12 & 1.15 & 1.20 & 1.03 \\
14.1 & 1.1 & 1.22 & 1.22 & 1.24 \\
17 & 1.16 & 1.13 & 1.13 & 1.32 \\
21.2 & 1.2 & 1.08 & 1.08 & 1.3 \\
28.3 & 1.02 & 1.16 & 1.38 & 1.3 \\
35.4 & 1.5 & 1.16 & 1.22 & 1.13 \\
42.4 & 1.5 & 1.3 & 1.3 & 1.2 \\
49.5 & 1.32 & 1.23 & 1.23 & 1.01 \\
56.6 & 1.64 & 1.43 & 1.43 & 1.2 \\
63.6 & 1.6 & 1.55 & 1.05 & 1.1 \\
70.7 & 1.8 & 1.17 & 1.23 & \\
\hline
\end{tabular}


Interpretation of hydrochemical analysis was carried out to establish the presence of leachates in three hand dug wells in the vicinity of the dump site. This was achieved by measuring certain ion concentrations in the samples. The major part of the Total Dissolved Solids (TDS) includes $\mathrm{HCO}_{3}, \mathrm{SO}_{4}{ }^{2-}$, and chloride of $\mathrm{Ca}^{2+}, \mathrm{Mg}^{2+} \mathrm{Na}^{2+}$.

The physical parameters measured are temperature, electrical conductivity, color, and turbidity.

Generally, the results of all the properties measured from the analyzed samples are higher than the Nigeria Standards for drinking water (NIS) limits. This therefore suggests that leachates from the dump have polluted the groundwater through the fractures in the subsurface.

Table 3. Intensity of fracture with electrode spacing at each location

\begin{tabular}{|c|c|}
\hline Locations & $\begin{array}{l}\text { Intensity of fracture with } \\
\text { electrode spacing }\end{array}$ \\
\hline$\overline{A S A} 01$ & $\begin{array}{l}\text { Fractureis encountered at shallow } \\
\text { depth but becomes more intense at } \\
\text { greater depths (from } A B / 2=35.4 \mathrm{~m} \text { ) }\end{array}$ \\
\hline ASA 02 & $\begin{array}{l}\text { Fracture is intense where } A B / 2 \\
=42.4 \mathrm{~m} \text { and at greater electrode } \\
\text { spacing. }\end{array}$ \\
\hline ASA 03 & $\begin{array}{l}\text { Presence of fractures at shallow } \\
\text { depth and at points } A B / 2=28.3 \mathrm{~m} \\
\text { and } 56.6 \mathrm{~m}\end{array}$ \\
\hline ASA 04 & $\begin{array}{l}\text { Fracture decreases with increasing } \\
\text { electrode spacing, and appreciable } \\
\text { amount of fractures occur at } A B / 2= \\
14.1 \mathrm{~m} \text { to } 28.3 \mathrm{~m} \text {. }\end{array}$ \\
\hline
\end{tabular}

\section{CONCLUSION AND RECOMMENDA- TION}

The study area, Owo, Southwestern Nigeria was investigated using Azimuthal Square Array dc resistivity method. This technique was used to delineate and characterize subsurface fracture of the area so as to have adequate knowledge of the location of such fractures through which leachates from landfill could flow and contaminate groundwater. This approach is able to identify and correlate the orientations of the surface and subsurface fractures, as well as their depth extent.

Fracture orientations obtained from the geophysical azimuthal soundings earlier conducted in the area agrees with those obtained from Azimuthal square array. The salient features of the effect of this method indicate the presence of a localized fracture system which shows mainly NE-SW, NW-SE, N-S trends and very good degree of fracture.

Scattered plots and Graphical interpretation of the technique indicate that a dominant fracture set is oriented NW/SE.

The presence and interconnectivity of fracture zones in almost all the sampled points even at the overburden in the study area provide pathway for easy movement of particles. The geophysical interpretation indicates presence of subsurface fractures as a pathway through which leachates from the dump site (as confirmed by the hydrochemical analysis) passes to pollute the groundwater as it affects the wells in the vicinity of the dump. This study therefore shows that the source of the contaminant of the water in the surrounding wells is the leachate from the dump site.

Hence, for domestic and industrial consumption, hand dug wells and boreholes should be drilled to a depth more than $20 \mathrm{~m}$ and further disposal of refuse on the site should be prevented to avoid deeper contamination.

\section{COMPETING INTERESTS}

Authors have declared that no competing interests exist.

\section{REFERENCES}

1. Risk GF. Detection of buried zones of fissured rock in geothermal fields using resistivity anisotropy measurements, in Geophysical papers submitted to the second U.N. symposium on the development and use of geothermal resources. San Francisco, California. 1975;78-100.

2. McDowell PW. Geophysical mapping of water filled fracture zones in rocks. International Association of Engineering Geology Bulletin. 1979;5(19):258-264.

3. Palacky GJ, Ritsema IL, De Jong SJ. Electromagnetic prospecting for groundwater in Precambrian terrains in the Republic of Upper Volta. Geophysical Prospecting. 1981;5(29):932-955.

4. Soonawala NM, Dence MR. Geophysics in the Canadian nuclear waste program--A 
case history. Proceedings of $51^{\text {st }}$ Society of Exploration Geophysicists Annual International Meeting, Los Angeles, Calif. 1981;83-98.

5. Taylor RW. Evaluation of geophysical surface methods for measuring hydrological variables in fractured rock units. U.S. Bureau of Mines Research Contract Report, contract H0318044. 1982;147.

6. Mallik SB, Bhattacharya DC, Nag SK. Behaviour of fractures in hard rocks-A study by surface geology and radial VES method. Geoexploration. 1983;5(21):181189.

7. Leonard-Mayer PJ. A surface resistivity method for measuring hydrologic characteristics of jointed formations. U.S. Bureau of Mines Report of Investigations. 1984;45.

8. Leonard-Mayer PJ. Development and use of azimuthal resistivity surveys for jointed formations, in Nielsen, D.M., and Curl, Mary, (eds.). National Water Well Association/U.S. Environmental Protection Agency Conference on Surface and Borehole Geophysical Methods in GroundWater Investigations. San Antonio, Texas. Proceedings. Worthington, Ohio. National Water Well Association. 1984;52-91.

9. Ogden AE, Eddy PS, Jr. The use of tripotential resistivity to locate fractures, faults and caves for siting high yield water wells, in Nielsen, D.M., and Curl, Mary, (eds.). National Water Well Association/ U.S. Environmental Protection Agency Conference on Surface and Borehole Geophysical Methods in Ground-Water Investigations. San Antonio, Texas. Proceedings. Worthington, Ohio. National Water Well Association. 1984;130-149.

10. Taylor RW, Fleming $\mathrm{AH}$. Characterizing jointed systems by azimuthal resistivity surveys. Ground Water. 1988;26(4):464474.

11. Lieblich DA, Haeni FP, Cromwell RE. Integrated use of surface-geophysical methods to indicate subsurface fractures at Tibbetts Road, Barrington, New Hampshire. U.S. Geological Survey Water-Resources Investigations Report. 1992;33.

12. Lieblich DA, Lane JW Jr, Haeni FP. Results of integrated surface-geophysical studies for shallow subsurface fracture detection at three New Hampshire sites. SEG $61^{\text {st }}$ Annual International Meeting.
Houston, Texas. Houston, Texas. 1991; 553-556.

13. Ritzi RW, Andolsek RH. Relation between anisotropic transmissivity and azimuthal resistivity surveys in shallow fractured carbonate flow systems. Ground Water. 1992;30(5):774-780.

14. Lane JW, Jr, Haeni FP, Wetson WM. Use of square-array direct-current resistivity method to detect fractures in crystalline bedrock in new Hamsphire. Groundwater U.S. Geological Survey Bulletin. 1995; 33(3):476-485.

15. Watson KA, Barker RD. Differentiating anisotropy and lateral effects using azimuthal resistivity offset Wenner soundings. Geophysics. 1999;64(3):739745.

16. George AM, Okwueze EE, Akpan AE, Uchegbu CJ. Comparative VES studies for the determination of fracture orientation using azimuthal square array and Schlumberger array data in Awi within the Oban Massif, S.E. Nigeria. Nigerian Journal of Physics. 2008;20(1):136-144.

17. Ehirim CN, Essien EE. Comparative investigation of offset Wenner, square and Schlumberger arrays in electrical anisotropy studies. Scientia Africa. 2009; 8(2):53-60.

18. Abdullahi NK, Batu MA, Masanawa AA. Fracture determination using azimuthal, Schlumberger and offset Wenner array in Basement complex of Northern Nigeria. Research Journal of Environment and Earth Sciences. 2012;4(7):747-755.

19. Okpoli CC, Igwe O. Electrical resistivity anisotropy in fracture delineation and characterization: A case study of IwaroAyepe Area, Southwestern Nigeria. Pacific Journal of Science and Technology. 2013; 14(2):488-497.

20. George AM, Okwueze EE, Abong AA. Azimuthal square array resistivity sounding of shallow subsurface fracture distribution in parts of the eastern basement complex of Nigeria. British Journal of Earth Sciences Research. 2014;2(1):1-18.

21. Lewis MR, Haeni FP. The use of surface geophysical techniques to detect fractures in bedrock. An Annotated Bibliography of U.S Geophysical Survey Circular. 1987; 987:14.

22. Habberjam GM. The effects of anisotropy on square array resistivity measurements. Geophysical Prospecting. 1972;5(20):249266. 
23. Darboux-Afouda R, Louis P. Contribution des mesures de l'anisotropicelectrique la recherche des aquifres de fracture en milieu cristallin au Benin. Geophysical Prospecting. 1989;5(37):91-105.

24. Sehli AS. Contribution of electrical prospecting to the geophysical study of discontinuous media. Paper presented at International symposium on applications of geophysics to water prospecting in arid and semi-arid areas, Paris, France; 1990.

25. Habberjam GM, Watkins GE. The use of a square configuration in resistivity prospecting. Geophysical Prospecting. 1967;5(15):221-235.

26. Habberjam GM. Apparent resistivity observations and the use of square array techniques, in Saxov, S., and Flathe, $\mathrm{H}$. (eds.). Geoexploration Monographs series. 1979;1(9):1-152.

27. Habberjam GM. Apparent resistivity, anisotropy and strike measurements. Geophysical Prospecting. 1975;23:211247.

28. Annor AE, Olasehinde PI, Pal PC. Basement fracture patterns in the control of water channels, an example from central Nigeria. Journal of Mining and Geology. 1990;26(1):5-11.

29. Okurumeh OK, Olayinka Al. Electrical anisotropy of crystalline basement rocks around Okeho, Southwestern Nigeria: Implications in Geologic Mapping and Groundwater Investigation. Water Resources Journal of $\mathrm{NAH}$. 1998;9:41-50.

(C) 2017 Eyinla and Eyinla; This is an Open Access article distributed under the terms of the Creative Commons Attribution License (http://creativecommons.org/licenses/by/4.0), which permits unrestricted use, distribution, and reproduction in any medium, provided the original work is properly cited.

Peer-review history:

The peer review history for this paper can be accessed here: http://sciencedomain.org/review-history/19104 